\title{
Tonal development and voice quality in the stops of Seoul Korean
}

\author{
Yu, Hye Jeong*
}

\begin{abstract}
Korean stops are currently undergoing a tonogenetic sound change, as found in the Seoul dialect in which a merged VOT of aspirated and lax stops induces F0 to be the primary cue for distinguishing the two stops and the lax stops have lower F0 than the aspirated stops. In tonal languages, low tone is produced with a breathy voice. This study investigated whether there are changes in voice quality with respect to the tonogenetic sound change of Korean stops. Two age groups speaking the Seoul dialect participated in this study: five females and six males born in the 1940s and 1950s and nine females and eight males born in the 1980s and 1990s. This study replicated previous findings of VOT and F0 and further examined $\mathrm{H} 1-\mathrm{H} 2, \mathrm{H} 1-\mathrm{A} 1$, and H1-A2 to see how they correlate with the sound change. In the older and younger generations, H1-H2, H1-A1, and H1-A2 were significantly lower after the tense stops than after the aspirated and lax stops, but they were not significantly different after the aspirated and lax stops. However, the younger females exhibited some different results for $\mathrm{H} 1-\mathrm{H} 2$ and $\mathrm{H} 1-\mathrm{A} 2$ than the older generation. In the younger females, the $\mathrm{H} 1-\mathrm{H} 2$ mean was higher after the aspirated stops than it was after the lax stops at the vowel onset, and the $\mathrm{H} 1-\mathrm{H} 2$ difference increased at the vowel midpoint. Although there was an inter-speaker variation in the results of $\mathrm{H} 1-\mathrm{H} 2$ and $\mathrm{H} 1-\mathrm{A} 1$, analyses of individual speakers showed that the $\mathrm{H} 1-\mathrm{H} 2$ and H1-A1 were higher after the lax stops than after the aspirated stops in the younger female speakers. These results indicate that lax stops tend to be breathier than aspirated stops in the younger female speakers. They also indicate that changes in voice quality are on Korean stops with tonal sound change, but are still developing.
\end{abstract}

Keywords: Korean stops, tonal development, breathiness, H1-H2, H1-A1, and H1-A2

\section{Introduction}

Korean has the three voiceless stops: aspirated, lax, and tense. Lax stops are commonly described as plain, lax, lenis, slightly aspirated or unaspirated, and breathy; aspirated stops are described as strongly aspirated and spread glottis; and tense stops are described as fortis, tense, laryngealized, creaky, unaspirated, and reinforced (Cho et al., 2002; Dart, 1987; Kim, 1965).

Previous studies on Korean stops showed that the three types of
Korean stops are fully distinguished from each other by Voice Onset Time (VOT) and the different degree of VOT is the primary cue in Korean stops; VOT is longest for aspirated stops, intermediate for lax stops, and shortest for lax stops (Cho et al., 2002; Han \& Weitzman, 1970; Kim, 1965; Lisker \& Abramson, 1964). However, in contemporary Seoul dialect VOT is not a crucial cue in the distinction of the aspirated and lax stops in phrase-initial position, because VOTs of the aspirated and lax stops partially or completely overlap (Silva, 2006). Kim (2000) found that tonal information of

\footnotetext{
* Hanshin University, hyejeong.u@gmail.com

Received 31 October 2018; Revised 28 November 2018; Accepted 29 November 2018

(C) Copyright 2018 Korean Society of Speech Sciences. This is an Open-Access article distributed under the terms of the Creative Commons Attribution Non-Commercial License (http://creativecommons.org/licenses/by-nc/4.0) which permits unrestricted non-commercial use, distribution, and reproduction in any medium, provided the original work is properly cited.
} 
Korean words is used in the perception of phonation contrasts by Korean listeners, and suggested that Korean is undergoing tonogenesis. Kim et al. (2002) and Kim (2004) also showed that fundamental frequency (F0) is an important perceptional cue for identification of the aspirated and lax stops. F0 was a redundant secondary cue in the distinction of Korean stops before the VOT overlapping of the aspirated and lax stops; the voice onset after the lax stops has lower F0 than after the aspirated and tense stops (Cho et al., 2002; Han \& Weitzman, 1970; Kim, 1965; Kim, 1970). A number of recent studies (Kang \& Guion, 2008; Kang, 2014; Kim, 2012, 2013, 2014; Kim, 2004; Kim \& Duanmu, 2004; Silva, 2006) have revealed the overlap in VOT between the aspirated and lax stops and the continuation of a robust F0 distinction in the two stops in younger Seoul dialect speakers, and they support the tonogenesis hypothesis in Korean. While VOT of the aspirated stops decreased and VOT of the lax stops increased over time, F0 difference between the two stops has been manifested over the following vowels and has become the primary phonetic feature in the distinction of the aspirated and lax stops. Furthermore, Kang \& Guion (2008) and Kang (2014) reported that F0 distinction among the three stops has increased over time despite the overlap in VOT, and Kang (2014) reported the F0 distinction is more enhanced in females compared to males.

The voice quality variation is characterized by a glottal configuration (Klatt \& Klatt, 1990). Ladefoged (1971) and Gordon \& Ladefoged (2001) proposed a simplified model of possible phonations by glottal constriction continuum, shown in (1).

\section{(1) Most open Most open}

Phonation type voiceless Breathy Modal Creaky Glottal Closure

From the left to the right of the continuum, phonation differences in voice are classified from voiceless voice, through breathy, modal, and then through creaky to glottal closure. The glottal open quotient (OQ) varies with changes in voice quality. For creaky voice, the vocal folds are tightly adducted but open along a small portion of the anterior and adducted vocal folds results in irregular voicing with a low glottal flow and subglottal pressure (Gordon \& Ladefoged, 2001; Keating et al., 2015). For breathy voice, the vocal folds are never completely adducted and incompletely closed vocal folds results in a high glottal flow with a low subglottal pressure (Hombert, 1979). For modal voice known as normal voice, the vocal folds are adducted enough to have regular voicing (Gordon \& Ladefoged, 2001).

Relative amplitude of the first two harmonics $(\mathrm{H} 1-\mathrm{H} 2)$ is the most popular measurement of voice quality. H1-H2 is well-suited to characterizing voice quality on a breathy to creaky continuum proposed by Ladefoged (1971), and Gordon \& Ladefoged (2001) (Esposito, 2010a, 2010b; Hanson, 1997; Holmberg et al., 1995; Keating \& Esposito, 2006). A higher H1-H2 is correlated with an increased OQ. Creaky voice usually shows weaker $\mathrm{H} 1$ than $\mathrm{H} 2$, and breathy voice shows stronger $\mathrm{H} 1$ than $\mathrm{H} 2$. Breathy voice shows greater H1-H2 than modal voice (Keating \& Esposito, 2006; Stevens, 2000). In Korean, H1-H2 of the tense stops is always the smallest (or negative) indicating that a voice quality is (laryngealized) creaky for the tense stops. $\mathrm{H} 1-\mathrm{H} 2$ is greater for the aspirated stops than that of the lax stops, indicating voice quality is breathier for the aspirated stops than for the lax stops (Ahn, 1999; Chang, 2007; Kang \& Guion, 2008). Cho et al. (2002) reported that $\mathrm{H} 1-\mathrm{H} 2$ was greater for

the lax stops than that of the aspirated stops, and they commented that different age of speakers or procedural differences could possibly cause the different H1-H2 results of Korean stops in Ahn's (1999) and their findings However, Kang \& Guion (2008) demonstrated that $\mathrm{H} 1-\mathrm{H} 2$ of aspirated stops is greater than that of lax stops in both younger and older Koreans.

Breathy voice quality is found in lower F0 syllables in tonal languages such as Vietnamese (Brunelle, 2009), Green Hmong (Andruski \& Ratliff, 2000) and Wu dialect spoken by Shanghai Chinese speakers (Jiang \& Kuang, 2016), and also in non-tonal languages such as Hindi (Ohala, 1973) and Gujarati (Khan, 2012). The phonation types of consonants interact with a tone of syllable. The phonetic tone raising hierarchy proposed by Hyman \& Schuh (1974) places breathy voice at maximally tone lowering on the continuum showing consonant-tone interaction, shown in (2).

(2)

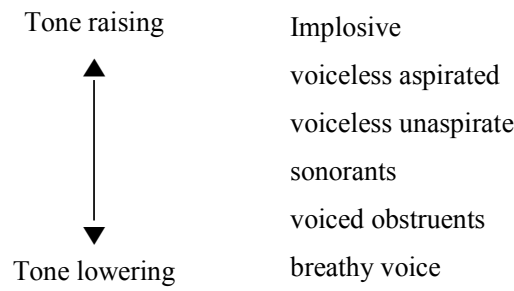

A VOT difference is diminishing between the aspirated and lax stops, and with tonogenetic sound change F0 contrast plays an important role in distinguishing the aspirated and lax stops. (Kang, 2014; Kim, 2012, 2013, 2014; Kim et al., 2002; Silva, 2006). In English, breathy voice and lower F0 in the vowel are perceptual cues to distinguish the voiced stops from the voiceless stops (Kingston, 2011). Breathy voice with slacker vocal folds typically occurs with low tone syllable. Breathy quality of Korean lax stops is induced in the onset of the following vowel and this breathy quality leads to F0 lowering. As F0 becomes a significant factor to distinguish the aspirated and lax stops in the contemporary Seoul dialect, breathy voice may be improved on the following vowel of the lax stops as part of the tonogenesis sound changes. Kim (2014, 2016) has reported that $\mathrm{H} 1-\mathrm{H} 2$ was higher (positive) at the voice onset after the lax stops than after the aspirated and tense stops in her younger female speakers. She stated that there is a correlation between tone and breathiness in accordance with the tonogenesis sound change in Korean, and $\mathrm{H} 1-\mathrm{H} 2$ is another important property with F0 involved in the sound change. Furthermore, she found that her female speakers kept having higher $\mathrm{H} 1-\mathrm{H} 2$ at the vowel midpoint after the lax stops than after the aspirated stops, indicating that they kept having breathier voice from the onset to midpoint of the following vowel after the lax stops than after the aspirated stops.

Besides $\mathrm{H} 1-\mathrm{H} 2$, voice quality can also be captured by the amplitude of $\mathrm{H} 1$ relative to the rest of the spectrum (i.e. H1-A1, H1-A2, H1-A3) (Blankenship, 2002; Esposito, 2010a, 2010b; Garellek \& Keating, 2011; Keating \& Esposito, 2006). A1, A2, and A3 correlate with the first, second, and third formant respectively. Measurements of spectral slope of H1-A1, H1-A2, and H1-A3 correlate with the abruptness of vocal fold closure (Hanson et al., 2001). Although the H1-H2 pattern of Korean stops differed from that in other previous studies, Cho et al. (2002) measured H1-A2 of Korean stops and reported that as in the results of H1-H2, H1-A2 of the tense stops was the smallest and H1-A2 of the lax stops was greater than that of the lax stops. Breathy voice is associated with 
higher values of H1-H2, H1-A1 and H1-A2. Wayland \& Jongman (2003) found that H1-H2 and H1-A1 distinguished breathy and modal voice in Khmer. Esposito (2010a) found that H1-H2, H1-A2, and H1-A3 distinguished breathy and modal voices in 10 languages or dialects. Blankenship (2002) found that $\mathrm{H} 1-\mathrm{H} 2$, and $\mathrm{H} 1-\mathrm{A} 2$ distinguished breathy voice from modal voice in Mazatec, and H1-A2 better distinguished breathy from modal phonation than H1-H2 in Chong. Khan (2012) found that H1-H2, H1-A1, and H1-A2 distinguished breathy and modal voices in Gujarati. Furthermore, Esposito (2004, 2010b) and Avelino (2010) reported gender differences in contrasting phonation types. In Esposito (2004, 2010b), the three phonations (breathy, modal, and creaky) in Santa Ana del Valle Zapotec were distinguished by $\mathrm{H} 1-\mathrm{H} 2$ for females and H1-A3 for males. In Avelino (2010), the two phonations (modal and laryngealized) in Yalálag Zapotec were distinguished by $\mathrm{H} 1-\mathrm{H} 2, \mathrm{H} 1-\mathrm{A} 2$, and $\mathrm{H} 1-\mathrm{A} 3$ for males and H1-A3 for females.

As mentioned above, lower F0 is associated with breathy voice in tonal languages. The F0 distinction of the aspirated and lax stops with the weakening VOT distinction may influence voice quality in Korean stops. This study investigated whether there is a change in voice quality of the phonation type contrast for Korean stops in accordance with the tonogenesis sound change. This study examined H1-H2, H1-A1, and H1-A2 at the onset and midpoint of the vowel after word initial stops. It also examined VOT and F0 of the stops to confirm the sound change. If the lax stops are breathier than the aspirated stops in younger Korean, H1-H2, H1-A1, and H1-A2 may be higher after the lax stops than after the aspirated stops.

\section{Method}

\subsection{Participants}

Two age groups of Korean speakers, who have lived in Seoul from birth participated in this study: older generation (OG) group and younger generation (YG) group. The participants in both age groups reported no history of articulatory or auditory problems. The OG group consisted of five females and six males (mean age: 66.9, standard deviation of age: 7.2). The YG group consisted of nine females and eight males (mean age: 28.8, standard deviation of age: 7.6), and eight of the YG group were university students. One male in the OG group had lived in Kangwon province for three years for his work, but he had come to Seoul every weekend to stay with his family. Other participants have never lived in other province or other countries.

\subsection{Stimuli and procedure}

The wordlist consisted of real Korean words having the three types of stops (aspirated, lax, and tense) at the three places of articulation (bilabial, alveolar, and velar) in the initial position:

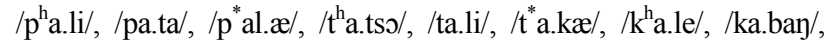
$/ t^{*}$ a.ma.kwi/. To omit an orthographic effect, pictures that the speakers can associate with the target words were presented to the speakers. Before an actual recording, the speakers had a practice recording. The speakers read the target words in a carrier sentence (i.e., ikətin __ ipnita '이것은 __입니다.') in a quiet room, and each speaker recorded three times. A recording was done using a Pyle-ProPMHM2 omnidirectional head-mouthed microphone at a sample rate of $44.1 \mathrm{khz}$ with Praat software. The microphone was about $3-5 \mathrm{~cm}$ from the corner of the mouth. A total of 756 tokens $(9$ words $\times 28$ speakers $\times 3$ times) were recorded four times for analysis. All measurements were taken in the Praat on Fourier spectrogram with a Gaussian window shape, a Frequency Range of 0-5,000 Hz, Window Length of 0.005 seconds, and dynamic range of $50 \mathrm{~dB}$.

The boundaries of each target stop were manually annotated with a Praat textgrid from the beginning of the burst of the target stop to the onset of periodicity in the following vowel in the wave form. The boundaries of the following vowel were also manually annotated using a Praat textgrid from the onset of periodicity to the offset of vowel F2. For the word initial stops, VOT, F0 at the onset and midpoint of the following vowel, and H1-H2, H1-A1, and H1-A2 at the onset and midpoint of the following vowel were automatically measured using Praat scripts. Some cases did not display a pitch track at the onset of the following vowel. In such cases, F0 was measured at a nearer point within $10 \mathrm{~ms}$ from the onset. The values of F0 for each subject were normalized because F0 varies according to subjects' age and gender. Each F0 was normalized by an individual speaker, by dividing each raw F0 value by the mean F0 for that speaker.

\subsection{Statistical analysis}

All analyses were performed in R 3.5.0 (R Core Team, 2018). Separate analyses were carried out on data from the two age groups sampled. Individual acoustic measurements were separately analyzed using linear mixed using linear mixed-effect modelling in the package lme4 (Bates et al., 2018). Main effect of phonation types was tested using the Anova function from the car package (Fox \& Weisberg, 2011) to attain $\chi^{2}$-value. When a significant difference was detected, a Tukey post-hoc test was used to see pair-wise differences between phonation types using the glht function from the multcomp package, with p-values adjusted for multiple comparisons (Hothorn et al., 2008). The effect of interaction between phonation type and gender sampled was tested using likelihood ratio test (LRT) with the Anova function comparing two models (one including the interaction and another with only additive effects of the two factors) to attain $\chi^{2}$-values.

\section{Results}

\subsection{VOT and F0}

Figure 1 gives mean and standard error values of VOT of the word initial stops produced by the OG and YG groups for each phonation type separately. The VOTs of the aspirated stops in the OG group were longer than those in the YG group, and the difference in VOT between the aspirated and lax stops was smaller in the YG group than in the OG group. 


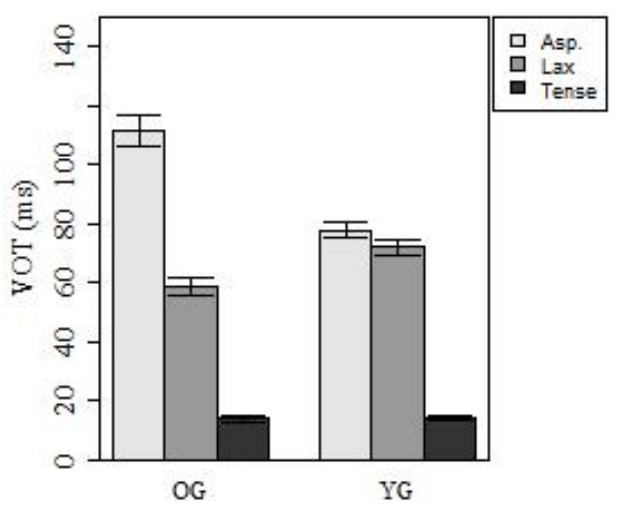

Figure 1. Mean VOT $( \pm 1$ standard error) in the three stops produced by the OG and YG groups.

The OG group showed a significant effect of phonation type on VOT $\left(\chi^{2}=488.07, p<0.001\right)$. The VOTs of the aspirated stops were significantly longer than that of the lax stops $(p<0.001)$, and the VOTs of the lax stops were significantly longer than that of the tense stops $(p<0.001)$. There was a significant effect of interaction of phonation type and gender $\left(\chi^{2}=32.23, p<0.001\right)$ on VOT. When comparing the VOTs of the males and females, the males produced significantly longer VOTs for the aspirated stops than the females $\operatorname{did}(p<0.001)$.

The YG group also showed a significant effect of phonation types on VOT $\left(\chi^{2}=439.66, p<0.001\right)$. The VOTs of the aspirated and lax stops were significantly longer than that of the tense stops $(p<0.001)$, but the VOTs of the aspirated and lax stops were similar $(\mathrm{p}=0.19)$. A significant interaction of phonation type and gender was found in the YG group $\left(\chi^{2}=0.75, p<0.05\right)$. The males produced significantly longer VOTs for the aspirated stops than the females $\operatorname{did}(p<0.05)$.

Figure 2 gives means and standard error values of normalized F0 after the stop release in the OG and YG groups separately. The differences in F0 between the three stops were greater in the YG group than in the OG group.

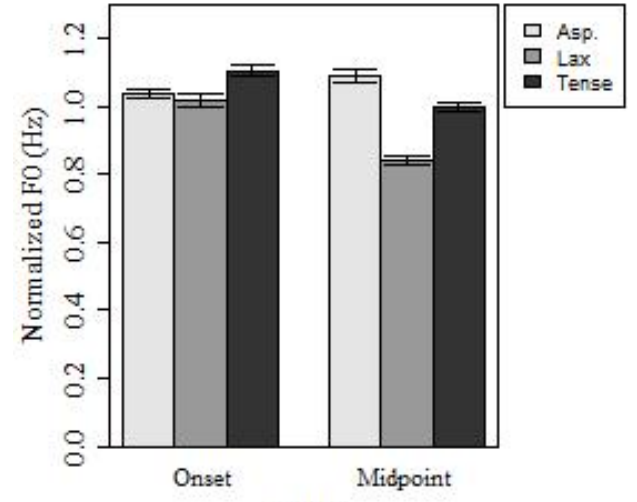

(a) $O G$

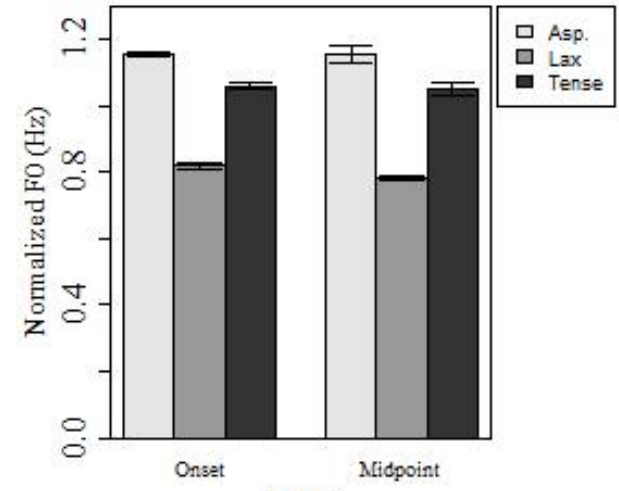

(b) YG

Figure 2. Mean of normalized F0 ( $₫ 1$ standard error) at the vowel onset and midpoint of the three stops produced by the OG and YG groups.

The OG group showed a significant effect of phonation type on F0 at the vowel onset $\left(\chi^{2}=179.19, p<0.001\right)$ and at the vowel midpoint $\left(\chi^{2}=132.31, p<0.001\right)$. The F0s after the aspirated and tense stops were significantly higher than those after the lax stops at the vowel onset and midpoint $(p<0.001)$. The F0s after the aspirated and tense stops were not different at the vowel onset $(p=0.3)$ but they were significantly different at the vowel midpoint $(\mathrm{p}=0.05)$. A significant interaction of phonation type and gender on F0 was found at the vowel onset $\left(\chi^{2}=32.23, p<0.001\right)$ and at the vowel midpoint $\left(X^{2}=32.23, p<0.001\right)$, corresponding to the previous studies such as Cho et al. (2002), Kim (2013) and Kang (2014). In the OG group, the females produced significantly higher F0s at the vowel onset and midpoint after the aspirated stops than the males did $(p<0.01)$. However, the males produced significantly higher F0 at the vowel onset after the tense stops than the females $\operatorname{did}(p<0.001)$.

The YG group also showed a significant effect of phonation type on F0 at the vowel onset $\left(\chi^{2}=709.31, p<0.001\right)$ and at the vowel midpoint $\left(\chi^{2}=846.04, p<0.001\right)$. The F0s at the vowel onset and midpoint after the aspirated stops were significantly higher than that of the tense stops $(p<0.001)$. However, unlike the results of previous studies, the F0s of the tense stops were significantly higher for the lax stops $(p<0.001)$ in the YG group. There was no significant interaction of phonation type and gender on $\mathrm{F} 0$.

The results of VOT and F0 in the three stops of the OG and YG groups were similar to the finding of previous studies (Kang, 2014; Kang \& Guion, 2008; Kim, 2012, 2013, 2014; Kim et al., 2002; Silva, 2006). The F0 distinction of the aspirated and lax stops in the YG group with the large overlap in VOTs of them supports the hypothesis of tonogenesis. Furthermore, the three Korean stops were 
significantly distinguished by F0 at the vowel onset and midpoint in the YG group.

\section{2. $\mathrm{H} 1-\mathrm{H} 2$, $\mathrm{H} 1-\mathrm{A} 1$, and $\mathrm{H} 1-\mathrm{A} 2$}

Figure 3-5 give mean and standard error values of $\mathrm{H} 1-\mathrm{H} 2$, H1-A1, and H1-A2 at the vowel onset and midpoint after stop release in the OG group and YG group separately.
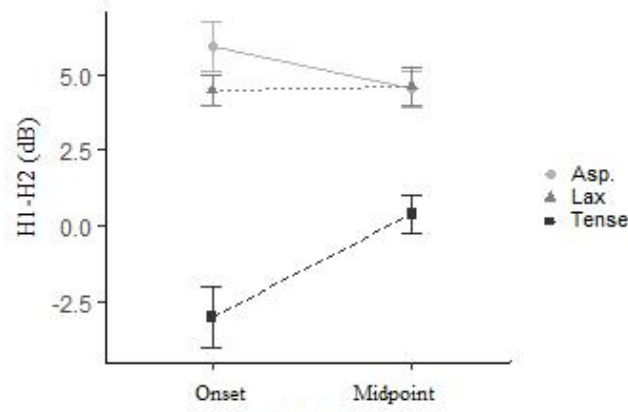

(a) $\mathrm{OG}$

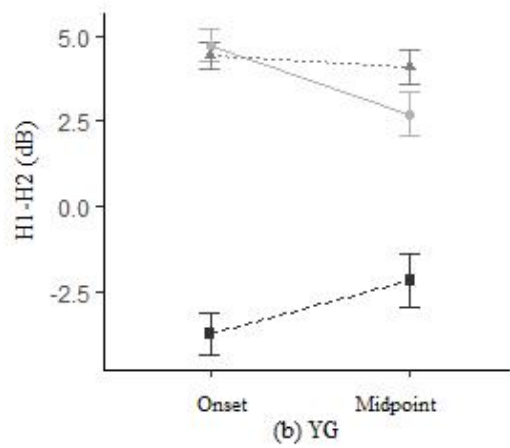

Figure 3. Mean $\mathrm{H} 1-\mathrm{H} 2( \pm 1$ standard error $)$ in the three stops produced by the $\mathrm{OG}$ and $\mathrm{YG}$ groups.
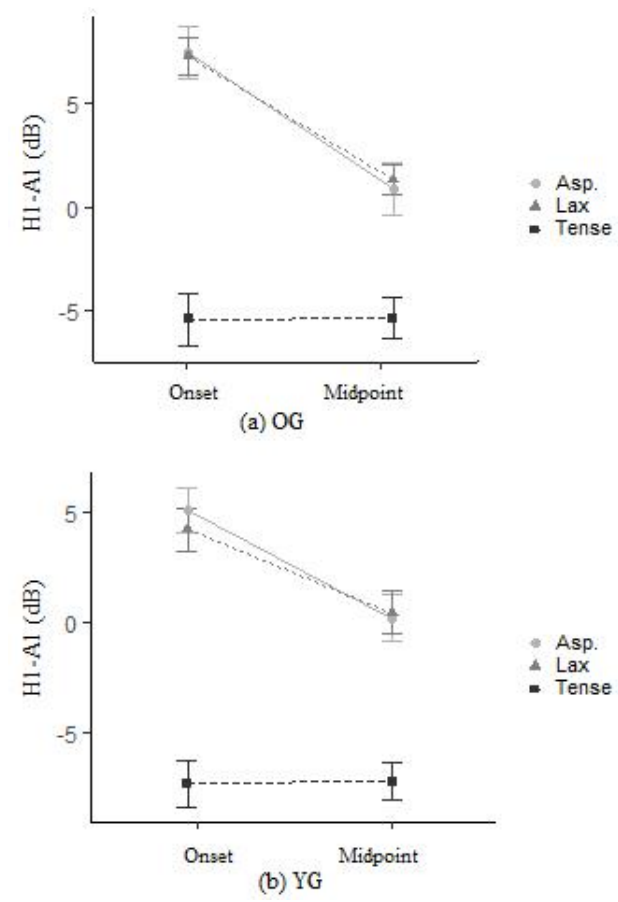

Figure 4. Mean H1-A1 $( \pm 1$ standard error) in the three stops produced by the OG and YG groups.
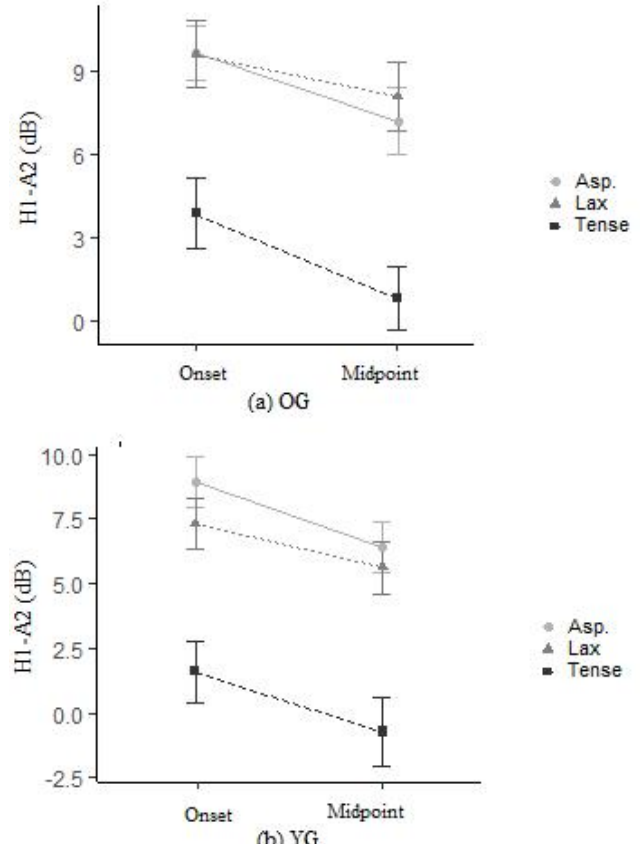

Figure 5. Mean H1-A2 $( \pm 1$ standard error $)$ in the three stops produced by the OG and YG groups.

The OG group showed that there was a significant effect of phonation types on H1-H2 $\left(\chi^{2}=85.7, p<0.001\right)$, H1-A1 $\left(\chi^{2}=97.35\right.$, $p<0.001)$, and H1-A2 $\left(\chi^{2}=19.28, p<0.001\right)$ at the vowel onset. At the vowel midpoint, there was also a significant effect of phonation types on H1-H2 $\left(\chi^{2}=48.35, p<0.001\right), \mathrm{H} 1-\mathrm{A} 1\left(\chi^{2}=31.92, p<0.001\right)$, and H1-A2 $\left(\chi^{2}=36.49, p<0.001\right)$. The H1-H2, H1-A1, and H1-A2 were significantly lower after the tense stops than after the aspirated and lax stops $(p<0.001)$ at the vowel onset and midpoint. However, they were not significantly different after the aspirated and lax stops at any position. The $\mathrm{H} 1-\mathrm{H} 2$ at the vowel onset after the aspirated stops were significantly higher in the females than in the males $\left(\chi^{2}=\right.$ $8.3, p<0.05)$.

The YG group also showed that there was a significant effect of phonation type on $\mathrm{H} 1-\mathrm{H} 2\left(\chi^{2}=202.22, p<0.001\right), \mathrm{H} 1-\mathrm{A} 1\left(\chi^{2}=103.65\right.$, $p<0.001)$, and H1-A2 $\left(\chi^{2}=38, p<0.001\right)$ at the vowel onset. At the midpoint, there was a significant effect of phonation types on H1-H2 $\left(\chi^{2}=143.56, p<0.001\right)$, H1-A1 $\left(\chi^{2}=46.58, p<0.001\right)$, and H1-A2 $\left(\chi^{2}=36.03, p<0.001\right)$. The values of H1-H2, H1-A1, and H1-A2 were significantly lower after the tense stops than after the aspirated and lax stops $(p<0.001)$ at the vowel onset and midpoint, but they were not significantly different after the aspirated and lax stops at any position. The H1-A2 at the vowel onset after the tense stops was significantly lower in the males than in the females $\left(\chi^{2}=\right.$ $10.2, p<0.05)$. The H1-H2 at the vowel midpoint after the aspirated stops was significantly lower in the females than in the males $\left(\chi^{2}=\right.$ $15.7, p<0.1)$.

\section{Summary and Discussion}

\subsection{VOT and $\mathrm{FO}$}

The VOT was no longer a phonetic cue to effectively distinguish the aspirated and lax stops in the YG group. While the VOT completely distinguished the three types of stops in the OG group, the VOT distinguished only the tense stops from the aspirated and 
lax stops in the YG group. The VOTs of the aspirated stops decreased and the VOTs of the lax stops increased in the YG group. This difference in VOTs between the $\mathrm{OG}$ and $\mathrm{YG}$ groups corresponds to previous studies (Kang, 2014; Kang \& Guion, 2008; Kim, 2012, 2013, 2014; Silva, 2006). On the other hand, the F0 completely distinguished the three Korean stops in the YG group, while the F0 distinguished only the lax stops from the aspirated and tense stops in the OG group. This indicates that not only VOT weight but also F0 weight differed between the OG and YG groups in terms of differentiation of the three stops in production. In addition, when comparing the VOTs and F0s for each place of articulation, the VOTs of the three stops were significantly different from each other at all three places of articulation in the OG group $(p<0.001)$, while the F0s after the three stops were significantly different from each other at all places of articulation in the YG group ( $p<0.05$ at bilabial, and $p<0.001$ at alveolar and velar). As F0 weight has increased as an important perceptual phonetic cue, it seems that the F0 contrast between the aspirated and tense stops increased in younger Korean speakers along with the enhanced F0 contrast between the aspirated and lax stops. However, the F0 difference of the aspirated and tense stops may disappear when tonal development is accomplished in Korean stops, because the aspirated and tense stops can be perfectly distinguished by VOT and because F0 does not influence the perception of tense stops (Kim, 2004). For raw F0, the difference between the aspirated and lax stops was greater in the female speakers than in the male speakers in the YG group (mean $\operatorname{diff}=48$ for the males; mean $\operatorname{diff}=87$ for the females) than in the OG group (mean diff $=38$ for the males; mean diff $=71$ for the females). This enhanced F0 difference in the females over time corresponds to the finding of Kang (2014).

\section{2. $\mathrm{H} 1-\mathrm{H} 2, \mathrm{H} 1-\mathrm{A} 1$, and $\mathrm{H} 1-\mathrm{A} 2$}

$\mathrm{H} 1-\mathrm{H} 2, \mathrm{H} 1-\mathrm{A} 1$, and H1-A2 well distinguished the tense stops having creaky voice from the other stops in the OG and YG groups. However, the aspirated and lax stops were not distinguished by H1-H2, H1-A1, and H1-A2 in both groups. For H1-H2, although the aspirated and lax stops were not separated, there was some difference in H1-H2s between the OG and YG groups. The mean $\mathrm{H} 1-\mathrm{H} 2$ at the vowel onset was higher after the aspirated stops than after the lax stops in the OG group, while the mean H1-H2s at the vowel onset after the aspirated and lax stops were similar in the YG group. At the vowel midpoint, the mean H1-H2s after the aspirated and lax stops were merged in the OG group while the mean $\mathrm{H} 1-\mathrm{H} 2$ after the lax stops was higher than that of the aspirated stops in the YG group. For H1-A1, the mean value after the aspirated and lax stops were similar at the vowel onset and midpoint in the OG and YG groups. For H1-A2, the mean value after the aspirated stops were similar or lower than that of the lax stops in the OG group, but the mean value after the aspirated stops were higher than that of the lax stops in the YG groups.

In Kim (2014), younger Seoul dialect speakers showed that mean $\mathrm{H} 1-\mathrm{H} 2 \mathrm{~s}$ after the aspirated and lax stops were similar at the vowel onset, but the mean $\mathrm{H} 1-\mathrm{H} 2$ of the lax stops was higher than that of the aspirated stops at the vowel midpoint. However, she reported a gender difference in $\mathrm{H} 1-\mathrm{H} 2$. In her younger female speakers, the H1-H2 was significantly higher after the lax stops than after the aspirated stops, and thus, the $\mathrm{H} 1-\mathrm{H} 2$ significantly distinguished the different types of Korean stops. However, in her younger male speakers, the H1-H2 was still higher after the aspirated stops than after the lax stops. Furthermore, although there was only one Korean female in Broersma (2010), the female showed higher H1-H2 at the vowel onset after the lax stops than after the aspirated stops. In this current study, the means of H1-H2, H1-A1, and H1-A2 at the vowel onset and midpoint were compared for the females and males in the OG and YG groups, as shown in Table 1 and 2.

Table 1. Means of H1-H2, H1-A1, and H1-A2 at the vowel onset after the aspirated and lax stops in the OG and YG groups

\begin{tabular}{c|c|c|c|c|c}
\hline & \multirow{2}{*}{$\begin{array}{c}\text { Phonation } \\
\text { type }\end{array}$} & \multicolumn{2}{|c|}{ OG } & \multicolumn{2}{c}{ YG } \\
\cline { 3 - 6 } & Female & Male & Female & Male \\
\hline \multirow{2}{*}{ H1-H2 } & Aspirated & 7.53 & 3.93 & 4.6 & 4.39 \\
\cline { 2 - 6 } & Lax & 5.10 & 3.28 & 5.11 & 3.49 \\
\hline \multirow{2}{*}{ H1-A1 } & Aspirated & 6.33 & 8.70 & 4.13 & 5.44 \\
\cline { 2 - 6 } & Lax & 6.87 & 7.20 & 4.97 & 3.66 \\
\hline \multirow{2}{*}{ H1-A2 } & Aspirated & 9.45 & 9.85 & 8.98 & 8.58 \\
\cline { 2 - 6 } & Lax & 9.57 & 9.46 & 8.52 & 6.10 \\
\hline
\end{tabular}

Table 2. Means of H1-H2, H1-A1, and H1-A2 at the vowel midpoint after the aspirated and lax stops in the OG and YG groups

\begin{tabular}{c|c|c|c|c|c}
\hline & \multirow{2}{*}{$\begin{array}{c}\text { Phonation } \\
\text { type }\end{array}$} & \multicolumn{2}{|c|}{ OG } & \multicolumn{2}{c}{ YG } \\
\cline { 3 - 6 } & Female & Male & Female & Male \\
\hline \multirow{2}{*}{ H1-H2 } & Aspirated & 4.03 & 5.84 & 1.65 & 4.38 \\
\cline { 2 - 6 } & Lax & 4.05 & 5.24 & 5.03 & 3.40 \\
\hline \multirow{2}{*}{ H1-A1 } & Aspirated & 1.04 & 2.04 & 0.30 & 0.01 \\
\cline { 2 - 6 } & Lax & 0.06 & 2.74 & 1.39 & 0.50 \\
\hline \multirow{2}{*}{ H1-A2 } & Aspirated & 8.26 & 7.48 & 5.66 & 6.51 \\
\cline { 2 - 6 } & Lax & 8.55 & 7.50 & 6.75 & 3.93 \\
\hline
\end{tabular}

In the OG group, at the vowel onset, the mean $\mathrm{H} 1-\mathrm{H} 2$ was higher after the aspirated stops than after the lax stops in the females, and the mean $\mathrm{H} 1-\mathrm{H} 2 \mathrm{~s}$ after the aspirated and lax stops were similar in the males. However, the H1-H2s after the aspirated and lax stops were not significantly different in the females $(p=0.7)$ and males $(p=0.2)$. However, as compared to in the males, the H1-H2s at the vowel onset after the aspirated stops were significantly higher in the females $(p<0.05)$, indicating the females produced breathier voice at the vowel onset after the aspirated stops than the males did. At the vowel midpoint, the H1-H2s of the aspirated and lax stops were similar in the females $(p=0.8)$ and males $(p=0.5)$, and the females and males showed similar $\mathrm{H} 1-\mathrm{H} 2 \mathrm{~s}$ for the aspirated $(p=0.2)$ and lax $(p=0.4)$ stops.

In the YG group, at the vowel onset, the mean $\mathrm{H} 1-\mathrm{H} 2$ was higher after the lax stops than after the aspirated stops in the females, while it was reverse in the males. However, the H1-H2s of the aspirated and lax stops were not significantly different in the females $(p=0.5)$ and males $(p=0.4)$. Unlike the females and males of the OG group, the females and males of the YG group produced $\mathrm{H} 1-\mathrm{H} 2$ similar at the vowel onset after aspirated $(p=0.8)$ and lax $(p=0.1)$ stops. However, at the vowel midpoint, the H1-H2s were significantly lower after the lax stops than after the aspirated stops $(p<0.001)$ in the females, while the $\mathrm{H} 1-\mathrm{H} 2 \mathrm{~s}$ after the aspirated and lax stops were not significant in the males $(p=0.5$ ). Furthermore, the $\mathrm{H} 1-\mathrm{H} 2 \mathrm{~s}$ at the vowel midpoint after the aspirated stops in the females were significantly lower than those in the males $(p<0.01)$, while the $\mathrm{H} 1-\mathrm{H} 2 \mathrm{~s}$ at the vowel midpoint after the lax stops were similar between the females and males $(p=0.1)$. In addition, in a comparison of the OG and YG groups for each phonation, the H1-H2s at the vowel midpoint after the aspirated stops in the YG females were 
significantly lower than those in the OG females $(p<0.05)$. These $\mathrm{H} 1-\mathrm{H} 2$ results indicate that there was a change in voice quality from the OG females to the YG females. It seems that the YG females produced less breathy voice for the aspirated stops than the OG females, while the females in the OG and YG groups produced similar breathy voice for the lax stops.

For H1-A1, there was not any significant difference in the OG and YG groups and between the OG and YG groups. For H1-A2, in the $Y G$ group the values were significantly lower after the aspirated stops than after the lax stops $(p<0.01)$ in the males, but the H1-A2s after the lax stops were not significantly different between the males and females $(p=0.3)$.

$\operatorname{Kim}(2014,2016)$ and Cho et al. (2002) reported that the H1-H2s of the three phonation types of Korean stops varied among the individual subjects. Figures 6,7 present the means of $\mathrm{H} 1-\mathrm{H} 2$ at the vowel onset after the three phonations for the individuals in the $\mathrm{OG}$ and YG groups, and variations of $\mathrm{H} 1-\mathrm{H} 2$ were shown among the speakers of the OG and YG groups. For $\mathrm{H} 1-\mathrm{H} 2$, despite the variations among the speakers; overall, the females tend to have higher $\mathrm{H} 1-\mathrm{H} 2 \mathrm{~s}$ after the lax stops than after the aspirated stops in the YG group when compared to in the OG group. Only one of the six females showed higher H1-H2s after the lax stops than after the aspirated stops in the OG group, but five of the nine females showed higher H1-H2s after the lax stops than after the aspirated stops in YG group. In Kim $(2014,2016)$, the H1-H2s at the vowel onset were significantly different among the three types of Korean stops in the younger female speakers. However, she also reported speaker variations in voice quality. In her study, some of the female speakers had higher $\mathrm{H} 1-\mathrm{H} 2$ after the aspirated stops than after the lax stops. This speaker variation may explain the reason why a significant difference was not found in $\mathrm{H} 1-\mathrm{H} 2 \mathrm{~s}$ of the aspirated and lax stops in the current study. For H1-A1, the females tend to have higher values after the lax stops than after the aspirated stops in the YG group. Two of the six females showed higher H1-A1 after the lax stops than after the aspirated stops in OG group, while six of the nine females showed higher H1-A1 after the lax stops than after the aspirated stops in YG group. For H1-A2, there was no difference in tendency between the $\mathrm{OG}$ and $\mathrm{YG}$ groups.

Studies on gender-correlated difference in sound change (Eckert, 1989; Labov, 1990) has reported that females lead sound change in speech. In the YG group, the females showed more VOT merger and F0 distinction in Korean stops than the males like the results of previous studies (Kang, 2014; Kim, 2014; Silva, 2006). The means of H1-H2s of the lax stops were lower than after the lax stops than after the aspirated stops in the YG females. The analyses of H1-H2 and H1-A1 values of the individuals show that more YG females took part in the sound change in Korean stops than the YG males did. There is a tendency that the YG group have breathier voice for the lax stops than for the aspirated stops, and in the YG the females have breathier voice for the lax stops than for the aspirated stops, as compared to the males. Thus, it seems that there is a change in voice quality that the lax stops with lower tone are breathier than the aspirated stops in younger Korean females. However, inconsistent patterns of $\mathrm{H} 1-\mathrm{H} 2$ and $\mathrm{H} 1-\mathrm{A} 1$ values indicate that the change in voice quality is in progress. So, it seems that the F0 distinction occurred simultaneously with the VOT merger, but the change of voice quality with respect to the F0 distinction is subsequent process in Korean stops. In accordance with the change of F0 role as VOTs of the aspirated and lax stops being merged, $\mathrm{H} 1-\mathrm{H} 2$ showed the voice
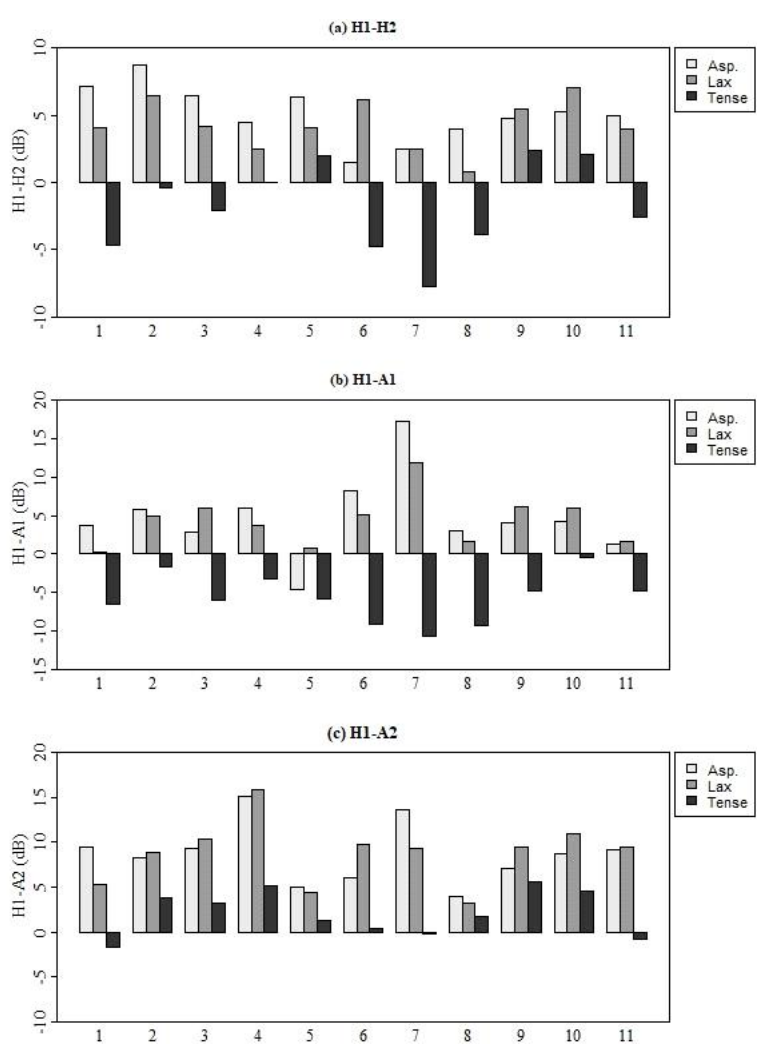

Figure 6. Means of H1-H2, H1-A1, and H1-A2 at the vowel onset of the three stops produced by the individuals of the OG group. The females are from 1 to 6 and the males are from 7 to 11 .

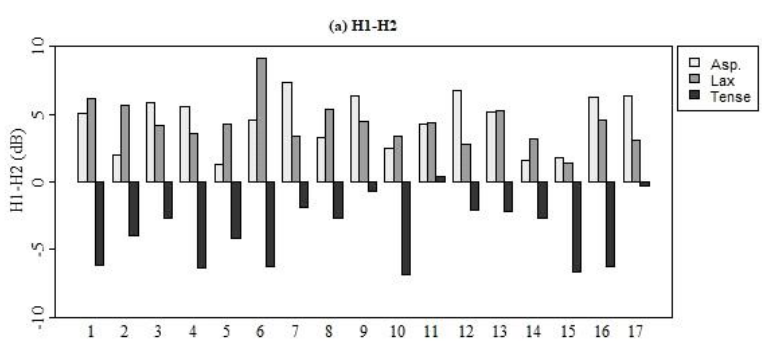

(b) $\mathrm{Hl}-\mathrm{Al}$

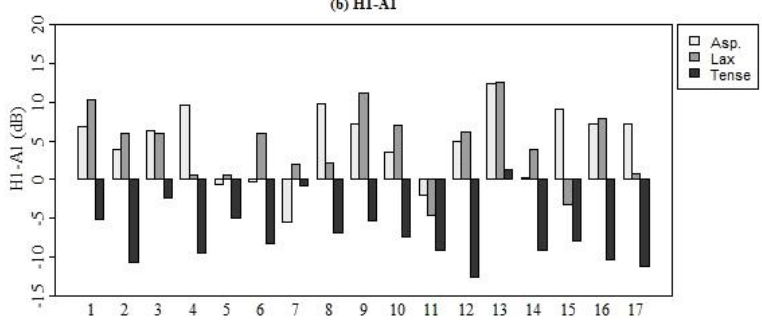

(c) $\mathrm{Hl}-\mathrm{A} 2$

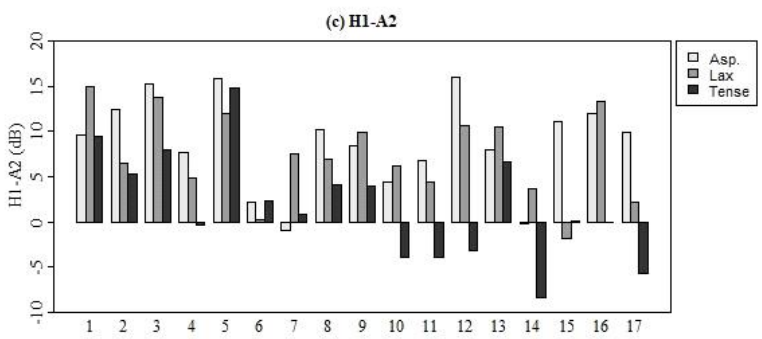

Figure 7. Means of H1-H2, H1-A1, and H1-A2 at the vowel onset of the three stops produced by the individuals of the YG group. The females are from 1 to 9 and the males are from 10 to 17 . 
quality change more than H1-A1 and H1-A2.

Studies on gender-correlated difference in sound change (Eckert, 1989; Labov, 1990) has reported that females lead sound change in speech. In the YG group, the females showed more VOT merger and F0 distinction in Korean stops than the males like the results of previous studies (Kang, 2014; Kim; 2014; Silva, 2006). The means of $\mathrm{H} 1-\mathrm{H} 2 \mathrm{~s}$ of the lax stops were lower than after the lax stops than after the aspirated stops in the YG females. The analyses of H1-H2 and H1-A1 values of the individuals show that more YG females took part in the sound change in Korean stops than the YG males did. There is a tendency that the YG group have breathier voice for the lax stops than for the aspirated stops, and in the YG the females have breathier voice for the lax stops than for the aspirated stops, as compared to the males. Thus, it seems that there is a change in voice quality that the lax stops with lower tone are breathier than the aspirated stops in younger Korean females. However, inconsistent patterns of $\mathrm{H} 1-\mathrm{H} 2$ and $\mathrm{H} 1-\mathrm{A} 1$ values indicate that the change in voice quality is in progress. So, it seems that the F0 distinction occurred simultaneously with the VOT merger, but the change of voice quality with respect to the F0 distinction is subsequent process in Korean stops. In accordance with the change of F0 role as VOTs of the aspirated and lax stops being merged, H1-H2 showed the voice quality change more than H1-A1 and H1-A2.

In summary, while the VOTs were overlapped between the aspirated and lax stops, F0 contrast was enhanced as the primary perceptual cue in the YG group. The females tend to have higher $\mathrm{H} 1-\mathrm{H} 2$ and $\mathrm{H} 1-\mathrm{A} 2$ for the lax stops than for the aspirated stops in the YG group as compared to in the OG group. This indicates that the females tend to produce breathier voice for the lax stops than the aspirated stops in the YG group. However, an inter-speaker variation was found in the $\mathrm{H} 1-\mathrm{H} 2$ and $\mathrm{H} 1-\mathrm{A} 2$ in the female of the YG group.

\section{References}

Ahn, H. (1999). Post-release phonatory processes in English and Korean: Acoustic correlates and implications for Korean phonology. Ph.D. Dissertation, University of Texas, Austin.

Andruski, J., \& Ratliff, M. (2000). Phonation types in production of phonological tone: The case of Green Mong. Journal of the International Phonetic Association, 30 (1-2), 37-61.

Avelino, H. (2010). Acoustic and electroglottographic analyses of nonpathological, nonmodal phonation. Journal of Voice 24(3), 270-280.

Bates, D., Maechler, M., Bolker, B., \& Walker, S. (2018). Package 'Ime4'. Vienna: R Foundation for Statistical Computing.

Blankenship, B. (2002). The timing of nonmodal phonation in vowels. Journal of Phonetics, 30(2), 163-191.

Broersma, M. (2010). 'Korean lenis, fortis, and aspirated stops: Effect of place of articulation on acoustic realization. Proceedings of the 11th Annual Conference of International Speech Communication Association (Interspeech 2010) (pp. 941-944). Makuhari, Japan.

Brunelle, M. (2009). Tone perception in Northern and Southern Vietnamese. Journal of Phonetics, 37(1), 79-96.

Chang, C. (2007). The status of voicing and aspiration as cues to Korean laryngeal contrast. Proceedings from the 43rd Annual Meeting of the Chicago Linguistic Society (Vol. 43, No. 1, pp. 31-45). Chicago: Chicago Linguistic Society.

Cho, T., Jun, S. A., \& Ladefoged, P. (2002). Acoustic and aerodynamic correlates of Korean stops and fricatives. Journal of Phonetics, 30(2), 193-228.

Dart, S. N. (1987). An aerodynamic study of Korean stop consonants: Measurements and modeling. The Journal of the Acoustical Society of America, 81(1), 138-147.

Eckert, P. (1989). The whole woman: Sex and gender differences in variation. Language Variation and Change, 1(3), 245-267.

Esposito, C. M. (2004). Santa Ana del Valle Zapotec Phonation. UCLA Working Papers in Phonetics, 103, 71-105.

Esposito, C. M. (2010a). The effects of linguistic experience on the perception of phonation. Journal of Phonetics, 38(2), 306-316.

Esposito, C. M. (2010b). Variation in contrastive phonation in Santa Ana del Valle Zapotec. Journal of the International Phonetic Association, 40(2), 181-198.

Fox, J., \& Weisberg, S. (2011) An R companion to applied regression ( $3^{\text {th }}$ edition). CA: Sage Publications. Retrieved from http://socserv. socsci.mcmaster.ca/jfox/Books/Companion on August 1, 2018.

Garellek, M., \& Keating, P. (2011). The acoustic consequences of phonation and tone interactions in Jalapa Mazatec. Journal of the International Phonetic Association, 41(2), 185-205.

Gordon, M., \& Ladefoged, P. (2001). Phonation types: A crosslinguistic overview. Journal of Phonetics, 29(4), 383-406.

Han, M. S., \& Weitzman, R. S. (1970). Acoustic features of Korean/P, $\mathrm{T}, \mathrm{K} /, \mathrm{p}, \mathrm{t}, \mathrm{k} /$ and $/ \mathrm{p}^{\mathrm{h}}, \mathrm{t}^{\mathrm{h}}, \mathrm{k} /$. Phonetica, 22(2), 112-128.

Hanson, H. (1997). Glottal characteristics of female speakers: Acoustic correlates. The Journal of the Acoustical Society of America, 10(1), 466-481.

Hanson, H. M., Stevens, K. N., Kuo, H. K. J., Chen, M. Y., \& Slifka, J. (2001). Towards models of phonation. Journal of Phonetics, 29(4), 451-480.

Holmberg, E. B., Hillman, R. E., Perkell, J. S., Guiod, P. C., \& Goldman, S. L. (1995). Comparisons among aerodynamic, electroglottographic, and acoustic spectral measures of female voice. Journal of Speech, Language, and Hearing Research, 38(6), 1212-1223.

Hombert, J. M. (1979). Consonant types, vowel height and tone. In V. A. Fromkin (Ed.), Tone: A linguistic survey (pp. 77-111). New York: Academic Press.

Hothorn, T., Bretz, F., \& Westfall, P. (2008). Simultaneous inference in general parametric models. Biometrical Journal, 50(3), 346363.

Hyman, L. M., \& Schuh, R. G. (1974). Universals of tone rules: Evidence from West Africa. Linguistic Inquiry, 5(1), 81-115.

Jiang, B., \& Kuang, J. (2016). Consonant effects on tonal registers in Jiashan Wu. Proceedings of the Linguistic Society of America (vol. 1, pp. 1-30).

Kang, K. H., \& Guion, S. G. (2008). Clear speech production of Korean stops: Changing phonetic targets and enhancement strategies. Journal of Acoustical Society of America, 124(6), 3909-3917.

Kang, Y. (2014). Voice onset time merger and development of tonal contrast in Seoul Korean stops: A corpus study. Journal of Phonetics, 45, 76-90.

Keating, P., Garellek, M., \& Kreiman, J. (2015). Acoustic properties of different kinds of creaky voice. Proceedings of the $18^{\text {th }}$ International Congress of Phonetic Sciences (pp. 0821.1-0821.5).

Keating, P., \& Esposito, C. (2006): Linguistic voice quality. UCLA Working Papers in Phonetics, 105, 85-91.

Khan, S. U. D. (2012). The phonetics of contrastive phonation in Gujarati. Journal of Phonetics, 40(6), 780-795. 
Klatt, D. H., \& Klatt, L. C. (1990). Analysis, synthesis, and perception of voice quality variations among female and male talkers. Journal of Acoustic Society of America, 87(2), 820-857.

Kim, C. W. (1965) On the autonomy of the tensity feature in stop classification (with Special Reference to Korean Stops). Word, 21(3), 339-359.

Kim, C. W. (1970). A theory of aspiration. Phonetica, 21(2), 107-116.

Kim, M. (2004). Correlation between VOT and F0 in the perception of Korean stops and affricates. Proceedings of INTERSPEECH 2004-8th International Conference on Spoken Language Processing (pp. 49-52).

Kim, M. R. (2000). Segmental and tonal interactions in English and Korean: A phonetic and phonological study. Ph.D. Dissertation, University of Michigan.

Kim, M. R., Beddor, P. S., \& Horrocks, J. (2002). The contribution of consonantal and vocalic information to the perception of Korean initial stops. Journal of Phonetics, 30(1), 77-100.

Kim, M. R., \& Duanmu, S. (2004). "Tense" and "Lax" stops in Korean. Journal of East Asian Linguistics, 13(1), 59-104.

Kim, M. R. (2012). Tonogenesis in Korean: Some Recent Speculations on the sound change. Korea Journal of Linguistics, 37(2), 243-283.

Kim, M. R. (2013). VOT merger and F0 maximization between the lax and aspirated stop in sound change. The Linguistic Association of Korea Journal, 21(2), 1-20.

Kim, M. R. (2014). Ongoing sound change in the stop system of Korean: A three- to two-way categorization. Studies in Phonetics, Phonology and Morphology, 20(1), 51-82.

Kingston, J. (2011). Tonogenesis. In M. van Oostendorp, C. J. Ewen, E. Hume, \& K. Rice (Eds.), The blackwell companion to phonology (pp. 2304-2333). Oxford: Blackwell Publishing.

Ladefoged, P. (1971). Preliminaries to linguistic phonetics. Chicago: University of Chicago.

Labov, W. (1990). The intersection of sex and social class in the course of linguistic change. Language Variation and Change, 2(2), 205-254.

Lisker, L., \& Abramson, A. S. (1964). A cross-language study of voicing in initial stops: Acoustical measurements. Word, 20(3), 384-422.

Ohala, J. J. (1973). The physiology of tone. Southern California Occasional Papers in Linguistics, 1, 1-14.

Stevens, K. (2000). Acoustic phonetics. Cambridge: The MIT Press.

Silva, D. J. (2006). Acoustic evidence for the emergence of tonal contrast in contemporary Korean. Phonology, 23(2), 287-308.

R Core Team (2018). R: A language and environment for statistical computing. Vienna: $\mathrm{R}$ foundation for statistical computing. Retrieved from https://www.R-project.org on August 1, 2018.

Wayland, R., \& Jongman, A. (2003). Acoustic correlates of breathy and clear vowels: The case of Khmer. Journal of Phonetics, 31(2), 181-201.

\footnotetext{
- Yu, Hye Jeong

Lecturer, Hanshin University

Department of English Language and Literature

36 Yangsan-dong, Osan-si

Gyeonggi-do 18101, Korea

Tel: 031-379-0430

E-mail: hyejeong.u@gmail.com

Fields of interest: Phonetics, Phonology, acquisition
} 